Int. J. Electrochem. Sci., 14 (2019) $3494-3508$

\title{
Metastable Pitting on 304 Stainless Steel in Cement Extract Solution with Different Concentration of $\mathrm{Cl}^{-}$
}

\author{
Xingguo Feng ${ }^{1,2}$, Yiwen $\mathrm{Xu}^{1}$, Xiangying Zhang ${ }^{1}$, Xiangyu $\mathrm{Lu}^{1}{ }^{*}$, Ruilong Shi ${ }^{1}$, Leyuan Zhang ${ }^{1}$, \\ Jing Zhang ${ }^{l}$, Da Chen ${ }^{l}$ \\ ${ }^{1}$ Jiangsu Key Laboratory of Coast Ocean Resources Development and Environment Security, Hohai \\ University, Nanjing 210098, Jiangsu, China \\ ${ }^{2}$ State Key Laboratory of Green Building Materials, 100024, Beijing, China \\ *E-mail: luxiangyu@hhu.edu.cn
}

doi: $10.20964 / 2019.04 .25$

Received: 7 December 2018 / Accepted: 18 January 2019 / Published: 10 March 2019

\begin{abstract}
Metastable pitting behavior of 304 stainless steels in cement extract solution ( $\mathrm{pH} 8$ ) with various concentration of $\mathrm{Cl}^{-}$was studied by Mott-Schottky plot, potentiodynamic polarization, and potentiostatic polarization, respectively. Nucleation rate and the probability of transformation from metastable to stable pitting on the stainless steel significantly increased when the concentration of $\mathrm{Cl}^{-}$ increased. The growth rate and re-passivation rate of individual metastable pitting also increased with the concentration of $\mathrm{Cl}^{-}$in the carbonated cement extract solution. Interestingly, differing from the wildly accepted view that the type of metastable pitting is characteristic of the kinds of metals or alloys and the type is not affected by the solution environment, in the present study, the types of metastable pitting on the 304 stainless steel gradually transformed from Type II to Type I when the concentration of $\mathrm{Cl}^{-}$increase in the pore solution. Additionally, high donor density suggests that the passive film has a high susceptive of pitting, but it may enhance the rate of passivation in the subsequent passivation process for the steel in the cement extract.
\end{abstract}

Keywords: stainless steel; pore solution; metastable pitting; growth rate; re-passivation rate

\section{$\underline{\text { FULL TEXT }}$}

(C) 2019 The Authors. Published by ESG (www.electrochemsci.org). This article is an open access article distributed under the terms and conditions of the Creative Commons Attribution license (http://creativecommons.org/licenses/by/4.0/). 